\title{
O Brasil nos relatos de viajantes ingleses do século XVIII: produção de discursos sobre o Novo Mundo
}

\author{
Brazil in the British travellers' accounts of the $18^{\text {th }}$ century: \\ discourses production on the New World
}

Ângela Domingues*

\section{RESUMO}

O conhecimento científico do Brasil é anterior ao período da abertura dos portos brasileiros ao comércio e navegação das nações europeias. Embora seja inegável a importância e a novidade trazidas pelas obras de John Mawe, Thomas Lindley, Henry Koster, Maximiliano de WiedNeuwied ou do barão de Eschwege, há que considerar que o Brasil tornou-se mais conhecido dos europeus do Setecentos graças aos roteiros, diários de viagens, mapas e vistas de marinheiros e traficantes, corsários e piratas que percorreram o litoral brasileiro durante o século XVIII. Assim como pelos registos produzidos por homens ilustrados como George Anson, James Cook, Joseph Banks, Charles Solander e Arthur Bowes Smith. O objectivo de muitos desses relatos produzidos ao longo do século XVIII define-se claramente do seguinte modo: corrigir a geografia do globo terrestre, diminuir os perigos da navegação e tornar mais conhecidos os costumes, artes e produtos da colónia brasileira.

Palavras-chave: conhecimento científico; relatos e diários de viagens; contrabando de informações.

\section{ABSTRACT}

The production and dissemination of scientific knowledge on Brazil are prior to the opening of Brazilian ports to the commercial and navigating activities of European nations. Although the importance and novelty of the works of John Mawe, Thomas Lindley, Henry Koster, Maximilian the Wied-Neuwied and the baron of Eschwege remain unquestionable, the knowledge on Brazil became available to the 18th century Europeans through log-books, journals, maps and drawings produced by sailors, smugglers, corsairs and pirates, that travelled along the Brazilian coast during that period, as well as through the records created by learned men such as George Anson, James Cook, Joseph Banks, Charles Solander, and Arthur Bowes Smith. The goals of these accounts produced during the 18th century were: to correct the geography of the earth, to diminish the dangers of navigations and to improve the knowledge on Brazilian uses, arts and natural products.

Keywords: scientific knowledge — Colonial Brazil; logs and journals; smuggling of information.

\footnotetext{
${ }^{\star}$ Departamento de Ciências Humanas - Instituto de Investigação Científica Tropical - Rua da Junqueira, no 86 - 1º, 1300-344 Lisboa - Portugal. adomingues@netcabo.pt.
} 
Alguns autores contemporâneos afirmam, de forma peremptória, que a descoberta científica do Brasil pelos europeus data do século XIX. Esses autores defendem que só após 1808 se teria iniciado um reconhecimento científico sistemático da colónia luso-brasileira por viajantes franceses, alemães, russos e ingleses, por indivíduos esclarecidos, lúcidos, dinâmicos e inovadores, detentores de interesses científicos, comerciais e económicos notórios em relação aos domínios coloniais europeus. E de igual modo, eram portadores de motivações teológicas, morais e estéticas face à humanidade dos 'novos mundos' que se revelavam à Europa setecentista e oitocentista como a América do Sul e o Pacífico. ${ }^{1}$ Nesse processo, e sobretudo devido a condicionantes de natureza política, os ingleses e alemães teriam sido inicialmente os protagonistas no processo de produção científica que renovou o conhecimento que a Europa do Oitocentos tinha sobre o Brasil. Os trabalhos de John Mawe, Thomas Lindley, Henry Koster, Maximiliano de Wied-Neuwied ou do barão de Eschwege, editados, reeditados e traduzidos a uma velocidade vertiginosa, renovaram os lugares-comuns usados na prosa de autores como o Abade Prévost ou M. de La Harpe que, em pleno 'século das luzes', descreviam o Brasil como lugar maravilhosamente estranho, encantado e selvagem com base em informações recolhidas por fontes portuguesas, francesas, inglesas e holandesas entre os séculos XVI e XVII.

Embora compreenda a posição defendida por esses autores e considere ainda, de forma lúcida, o peso do controle efectivo que as coroas ibéricas detiveram em relação à divulgação de informações actualizadas sobre as colónias sul-americanas através de uma posição política clara e consciente dos governos de Portugal e Espanha, parece-me que a premissa acima defendida não considera, com justeza, o conhecimento que a Europa do Setecentos foi acumulando sobre os domínios coloniais sul-americanos. O processo foi progressivo e lento e as descrições foram alteradas e corrigidas à medida que a ciência europeia e a sua metodologia se renovavam e evoluíam, que os modos de observação e as perspectivas valorizadas nas formas de encarar outras realidades se alteravam e os instrumentos de observação científica se tornavam mais exactos e precisos. Por exemplo, o surgimento de relógios de pêndulo, de novos aparelhos de astronomia e física ou o aperfeiçoamento de instrumentos ópticos com aplicação na astronomia e na náutica, de sextantes e octantes, de barómetros e termómetros, permitiram a observação e o registo do mundo como ainda não tinha sido visto ou registado.

Um estudo sistemático realizado nas Philosophical Transactions, revista oficial da britânica Royal Society, é paradigmático no que diz respeito ao in- 
teresse e esforço feitos pela elite científica britânica que constituía uma academia tão prestigiada como essa através de Jean de Léry, Hans Staden, Wilhelm Piso ou Fernão Cardim, assim como por intermédio de académicos britânicos e portugueses, diplomatas e particulares residentes em Londres ou espalhados por outros cantos do mundo, pois todos buscavam um conhecimento mais exacto do Brasil, da sua geografia, produções naturais, habitantes, costumes e comportamentos. Frente a tal interesse, informações ou testemunhos trazidos por portugueses que eram fellows da Royal Society, como Jacob de Castro Sarmento, por amigos desses académicos, como era o caso de um cavalheiro anónimo que tinha vivido durante longo tempo em Cerro Frio, ou ainda por diplomatas com conhecimento directo da realidade sul-americana, como o enviado extraordinário Luís Pinto de Sousa Coutinho contribuíam para uma renovação gradual do conhecimento detido por essa elite sobre o Brasil. $^{2}$

Na construção do conhecimento que a Europa ilustrada tinha sobre o Brasil — de que é paradigmático o conhecimento plasmado nos artigos das Philosophical Transactions - privilegiava-se a observação directa, sobretudo quando era realizada em função dos novos interesses e metodologias científicas ao utilizar instrumentos de precisão. Afinal eram estas metodologias e instrumentos que o 'século das luzes' tinha passado a deter.

Quanto à fonte da informação, ela podia ser tanto a viagem e os depoimentos de indivíduos instruídos, tais como a produção de informação textual, iconográfica e cartográfica ou a recolha de produtos a eles associados, como também a experiência laboratorial ligada à realização de testes em produtos naturais brasileiros (particularmente minerais e vegetais). Viagens, experiências e observações efectuadas directamente da realidade criavam junto dos leitores de relatos um sentimento de veracidade e credibilidade, clarificavam dúvidas e desmentiam efabulações. Outra garantia de fiabilidade era também a bagagem intelectual do viajante: a sua formação, preparação/treino, conhecimentos científicos e linguísticos, quando era o caso disso. ${ }^{3}$

Para além das observações e dos registos que 'homens de ciência' fizeram sobre o litoral brasileiro, considero igualmente que o conhecimento produzido durante o século XVIII por marinheiros e traficantes, corsários e piratas, registado sob a forma de roteiros, diários de viagens, mapas e vistas, contribuiu, de forma desigual mas sempre válida, para que o território brasileiro fosse mais bem conhecido pela elite europeia. Se não da terra, do interior do subcontinente sul-americano e das jazidas de ouro e diamantes que se sabia existir, mas não localizar, seguramente os seus relatos trouxeram informações 
do litoral, dos portos, da linha de costa que tiveram uma importância notória para marinheiros, viajantes e particulares com interesses científicos e comerciais. ${ }^{4}$

Ora, nesse sentido, parto do princípio de que o conhecimento geográfico, natural, económico, 'antropológico' e a ocupação humana e urbana do território sul-americano, tal como perpassa nas fontes analisadas, contribuiu para a construção do 'conhecimento científico' que a elite britânica deteve em relação ao Brasil ao longo do Setecentos. Da mesma maneira, considero que a 'captura' desse conhecimento, decorrente de uma observação directa, e a forma como foi registado não obedeceram aos mesmos métodos e princípios durante o período considerado, dependendo da forma como a 'ciência' se pensava e definia, nomeadamente em relação ao papel que social e filantropicamente se atribuía (e que seguramente não permaneceu imutável ao longo do século XVIII). ${ }^{5}$ Parto igualmente do pressuposto de que a formação, informação e interesse dos viajantes determinaram o que estes viram e o que lhes interessava, condicionando ainda a forma como descreveram ou representaram esses conhecimentos.

Não obstante, os objectivos de muitos desses relatos definem-se claramente do seguinte modo: corrigir a geografia do globo terrestre, diminuir os perigos da navegação e tornar melhor conhecidos a ocupação, costumes, artes e produtos de países estrangeiros. ${ }^{6} \mathrm{E}$, consequentemente contribuir para um melhor conhecimento natural, geográfico, humano, económico, 'antropológico’ e logo científico, do Novo Mundo.

\section{VIAJANTES, DIÁRIOS DE VIAGEM E ESCALAS}

É inegável que os portos brasileiros tiveram uma importância estratégica e logística na navegação atlântica, apesar das restrições impostas ao acesso e permanência de estrangeiros em território brasileiro, constantemente expressas nas directrizes emanadas do governo central. ${ }^{7}$ Navios e frotas com as mais variadas composições, enviados por monarcas, companhias comerciais ou armadores particulares e com as mais diferentes finalidades - sejam elas científicas, comerciais, de reconhecimento ou espionagem - , tocaram o litoral brasileiro em Porto Seguro, Santa Catarina, Salvador da Bahia, Olinda, Cabo Frio, Ilha Grande, Angra dos Reis, Parati e, acima de tudo, no Rio de Janeiro. Esses navios e frotas privilegiavam, nas suas escalas no Atlântico Sul, portos seguros que tivessem capacidade de fornecer rápida e eficazmente aos 
navios ancorados alimentos, água, madeira para reparos e combustível. Nesse sentido, os portos brasileiros eram comummente frequentados por navios ingleses, holandeses e franceses que procuravam reabastecimento de água e víveres e reparo das embarcações apanhadas por violentas tempestades no meio do oceano ou quando tinham problemas sanitários a bordo.

Em pleno 'século das luzes', as tripulações já não se podiam comparar aos piratas e corsários que, em período anterior, sulcavam profusamente as águas atlânticas e que, não obstante os seus propósitos mais óbvios foram também produtores de conhecimento geográfico sobre o litoral brasileiro. Os viajantes do período iluminista consideravam-se súbditos leais, socialmente responsáveis, executando uma missão (política, comercial, científica) sob o estandarte de uma nacionalidade e de um Estado, que lhes conferia um sentimento de identidade e superioridade. Ora, dentre todos os povos, os ingleses consideravam-se os mais civilizados, honrados, prósperos e esclarecidos. ${ }^{8}$

De muitas dessas viagens resultaram testemunhos textuais, cartográficos e iconográficos, alguns logo impressos nas tipografias das principais cidades europeias, outros ainda inéditos, mas provavelmente conhecidos e utilizados por quem fazia viagens semelhantes e que pretendia aprender com a experiência e a prática de outros a maneira como se navegava por águas do Atlântico Sul.

Em muitas dessas viagens eram associados objectivos científicos às actividades de corso e pirataria, entre eles o objectivo de correcções das coordenadas terrestres, das correspondentes descrições geográficas e representações cartográficas. Com relação a estas últimas, mencione-se a de George Anson, comandante do navio Centurion, oficialmente enviado pelo soberano britânico em viagem de circunavegação entre os anos de 1740 e 1744. Durante a travessia do Atlântico, ocorreu uma situação sanitária grave a bordo com a doença e a morte de alguns tripulantes provocadas por febres associadas a navegações morosas em climas equatoriais. Perante essa situação, Anson aportou à ilha de Santa Catarina, onde desembarcou os enfermos, limpou e desinfectou os navios com vinagre, fez os reparos necessários e providenciou a quantidade de água, víveres e madeira necessária à prossecução da viagem. Nesse episódio, a ilha, o clima, o enquadramento geográfico e a ocupação humana são descritos em pormenor ao relatar canais de navegação, fortificações, núcleos de povoamento, fazendas, vegetação natural, produção agrícola, gado, animais selvagens e insectos. ${ }^{9}$

Um dos aspectos interessantes desse relato consiste no facto de ressaltar as peculiaridades da colonização portuguesa nesta parte afastada do Império, 
pois os europeus que aqui estavam estabelecidos não eram colonos emigrados ligados ao trabalho da terra, mas "vagabonds and outlaws, who fled thither from all parts of Brazil”, súbditos da coroa cuja autoridade reconheciam apenas tacitamente, ao serem governados por um capitão sem poder efectivo. Estabeleciam com as tripulações dos navios estrangeiros relações amigáveis e hospitaleiras e se beneficiavam de um comércio que lhes escoava os excedentes agrícolas e fornecia matérias-primas europeias. Os princípios de 'comércio justo' com esses 'honestos vagabundos' foram subvertidos quando uma autoridade efectiva, a de D. José Silva da Paz, brigadeiro do exército português, se tinha estabelecido com os seus soldados e dedicado ao controlo das trocas comerciais entre os naturais e os recém-chegados, que eram taxadas a preços altíssimos. ${ }^{10}$

Outros viajantes tinham intuitos puramente científicos, relacionados com observações geográficas, astronómicas e científicas-naturais do litoral sul-americano. Dentre eles, James Cook, Joseph Banks e Charles Solander que, a bordo do navio Endeavour em viagem de circunavegação destinada à observação do trânsito de Vénus e à correcção de coordenadas terrestres e representações geográficas, tocaram o porto do Rio de Janeiro a 13 de Novembro de 1768. Não obstante a firme intenção dos viajantes em desembarcarem na Guanabara, tendo o vice-rei conde de Azambuja suspeitado que mais não eram que piratas e contrabandistas, não autorizou que desembarcassem. Evocando o zelo com que o Rei Fidelíssimo guardava os seus portos sul-americanos, bem como o facto de os ingleses não estarem munidos com as credenciais necessárias, o conde considerava que faltaria "à sua obrigação e à sua honra" se autorizasse a entrada dos membros da expedição do Endeavour em território luso-brasileiro e permitisse a realização de observações de natureza científica. ${ }^{11}$

Os protestos de Joseph Banks são bem conhecidos. Argumentava o futuro presidente da Royal Society que:

I am a gentleman and one of fortune sufficient to have (at my one expense) fitted out that part of the expedition under my own direction; which is intended to examine the Natural History of the countries we shall touch. For the execution of this understanding, I have with me proper People who, as well as myself, have made that science their particular study. To all these, His Britannic Majesty was graciously pleased to allow conveniences and accommodations on board this ship, on consideration to the use which from such researches might accrue to mankind in general. ${ }^{12}$ 
A natureza rica, exótica e exuberante da baía de Guanabara só ficou ao alcance desses notáveis súbditos de Sua Majestade Britânica com as incursões sub-reptícias de Banks a terra e a inclusão de espécies naturais entre os vegetais e animais que entravam a bordo para fornecimento da cozinha. ${ }^{13}$ De acordo com John Hawkesworth, autor de An account of the voyages undertaken by the order of his Present Majesty for Making Discoveries (Londres, 1773), Banks teria conseguido recolher cerca de 320 espécies vegetais.

O porto do Rio de Janeiro, escala quase obrigatória de quem viajava no Atlântico Sul, foi também descrito em 1787 por Arthur Bowes Smith que, a bordo do navio Lady Penrhyn, realizava uma viagem de natureza diferente da anteriormente relatada já que transportava mulheres degredadas para as colónias australianas. Bowes Smith descreve, de forma vívida, a baía de Guanabara e a cidade do Rio de Janeiro com suas ruas compridas e largas, as casas de boa construção com os habitantes afáveis, a grandeza do aqueduto com os seus arcos regulares, obra considerada pelo inglês como digna de se ver, e a elegância de igrejas e conventos. A beleza verdejante dos morros em redor da baía é também exaltada, a par da variedade das produções naturais que são recolhidas como aves, plumas, borboletas, insectos, folhas, flores e conchas. ${ }^{14}$

Interesses mercantis relacionados com a busca de novos mercados e produtos são os que se associam à viagem de Thomas Lindley. Um navio sob sua direcção partiu do Cabo da Boa Esperança a 25 de Fevereiro de 1802, chegou a Santa Helena no início de Março e três semanas depois partiu na direcção de Salvador. Vale dizer que esta cidade só podia ser escalada pelos navios estrangeiros por um período limitado e com problemas técnicos ou para aguada e aprovisionamento. Qualquer tentativa de comércio era inibida seja através da inspecção de oficiais da alfândega e da justiça, seja pela vigilância de soldados, assim como, pela supervisão de um barco-patrulha. Reconhecendo estas condicionantes, Lindley rumou para o Rio de Janeiro. Contudo, ventos contrários e uma costa perigosa 'empurraram-no' na direcção de Porto Seguro, uma cidade de menores dimensões, governada por um capitão-mor permissivo, que lhe concedeu "permission to trade, ordering a new rudder and tredering every refreshment which the place afforded". As informações recebidas por Thomas Lindley sobre as produções naturais eram selectivas, incidindo sobre os géneros com valor comercial na Europa, como o açúcar e, particularmente, o pau-brasil. Foi um navio carregado com essa madeira, mesmo com o conhecimento de ser objecto de comércio ilícito que, a 2 de Julho, esse navegador foi capturado no rio Caravelas por um oficial e alguns soldados e 
remetido para Porto Seguro. Lindley seguiria sob escolta para a Bahia, acusado de contrabandear pau-brasil. ${ }^{15}$

É essa perspectiva comercial da cidade da Bahia, considerada do ponto de vista comercial como a mais dinâmica da costa do Brasil, juntamente com o Rio, que sobressai na descrição de John Turnbull (1800), um agente comercial inglês que, com autorização da Companhia das Índias Orientais, deixou Portsmouth em Maio de 1800, também com o objectivo de averiguar o estabelecimento de novas rotas e a exploração de novos produtos comerciais (França, 2003, p.232). Relata-se, de novo, a cautela e o controle das autoridades portuárias que inspeccionaram internamente o navio e colocaram um navio-patrulha a vigiá-lo. Thurbull foi recebido pelo governador-geral da Bahia, que o interrogou. E os mapas, diários de bordo e outros documentos que trazia foram examinados pelos oficiais que rodeavam o governador-geral, possivelmente com funções administrativas e militares. Entre as narrativas mencionadas dá-se particular ênfase à actividade comercial com o reino e com os portos africanos, relacionando-se a exploração mineira com a necessidade constante de mão-de-obra africana, e à construção naval, salientandose a dependência de ferro, alcatrão e breu que vêm do reino. A cidade é descrita com as inúmeras igrejas, o cerimonial religioso da celebração dos ofícios divinos e das procissões, assim como a etiqueta e a opulência que rodeava o governador-geral da Bahia.

TOCAR O LITORAL BRASILEIRO: COMPETIÇÃO COMERCIAL, POLÍTICA E ESTRATÉGICA ENTRE NAÇÕES

$\mathrm{Na}$ análise dos relatos que mencionei e de outros menos relevantes mas que, pela temática, se podem enquadrar nas categorias mencionadas como corso e pirataria, científica e comercial, há, antes de mais, que considerar que os portos frequentados e descritos não são portos pequenos, provavelmente mais frequentados por quem praticava o contrabando. Contrariamente, são portos que, pelas suas dimensões, coincidem com os núcleos urbanos mais consideráveis, associados a redes comerciais inter-regionais e transatlânticas com capacidade para receber e reparar navios de grande porte. Nas fontes consideradas são definidos como: "the most eligible ports for our cruises to refresh" (Chaplain, 1748, p.53). Dentre estes, o Rio de Janeiro, centro comercial e administrativo de importância incontestável, uma das cidades mais próspe- 
ras do hemisfério Sul e porta de entrada para as minas de ouro, concentrava a atenção internacional e era uma das escalas preferidas dos navegantes. ${ }^{16}$

Os relatos analisados, manuscritos e impressos descrevem minuciosamente as especificidades marítimas, geográficas e humanas do litoral brasileiro ao tratarem a profundidade do oceano, a direcção de ventos e correntes, os baixios e as ilhas. Dão particular relevância às peculiaridades naturais ou edificadas que permitissem identificar um local visto do mar e atender minuciosamente a outros sinais considerados importantes na entrada de barras e ancoradouros. Mas noticiam ainda, e com especial cuidado, a presença de outros europeus em terras coloniais como a ocupação humana estabelecida fora do reino, a personalidade e comportamento distintos dos europeus fora da Europa, as mudanças políticas e administrativas que afectavam o relacionamento dos viajantes com a população local, bem como os proventos económicos extraídos de solo colonial, quer estes incidissem sobre produções naturais ou sobre produtos aclimatados e cultivados.

Nesta última questão recaía, em muitos casos, a atenção desses viajantes que eram também mercadores com prioridades comerciais claras e súbditos fiéis de Estados que queriam enriquecer-se economicamente e desenvolver-se civilizacionalmente através da conquista de vantagens comerciais sobre novos espaços geográficos, novos produtos e novas rotas. Maior riqueza privada equivalia a maior prosperidade colectiva; maior desafogo económico dos particulares conduziria ao progresso e ao bem-estar social.

Era ainda nesta óptica em que as ambições e objectivos pessoais se correlacionavam com um horizonte mais vasto, o da nação, que os súbditos das monarquias europeias encontravam justificação e legitimidade para o secretismo com que portugueses e espanhóis rodeavam os seus domínios ultramarinos: "In all states whose wealth is immediately derived from mercantile sources, the greatest care should be taken to preserve their commerce from every species of depredation or violence that may be pointed against it, through the jealousy or envy of less successful trading nations". ${ }^{17}$ A partir do momento em que novas nações competiam e expandiam o seu poder em nível internacional, considerava-se o comércio como um aspecto vital dessa competição à escala global.

Contudo, a atitude dos governos ibéricos em relação a essa questão não se pode reduzir a um aspecto puramente comercial. Subjacentes aos limites impostos pelas coroas de Portugal e Espanha às restrições na circulação da informação sobre as colónias estão também motivos políticos e estratégicos. Para além de tudo, percebia-se claramente que não só o governo, mas também os particulares, e principalmente comerciantes e mercadores, tinham to- 
do o interesse em preservar informação para ter vantagens económicas ligadas ao comércio exclusivo ou preferencial de determinados produtos e ao lucro. ${ }^{18}$

Maria Fernanda Bicalho, num estudo notável sobre a cidade do Rio de Janeiro, refere que "A frequência das arribadas estrangeiras nas praças coloniais do Brasil e a ampla circulação de informações sobre elas contradiziam a cautela e o cuidado metropolitanos em torno do segredo e da clausura dos seus portos ultramarinos, desmistificando a ideia de exclusividade do desembarque, do conhecimento e até mesmo dos negócios dos súbditos portugueses naquelas paragens". ${ }^{19}$ A questão talvez mereça também uma outra reflexão uma vez que a frequência dos portos brasileiros por navios estrangeiros era inevitável. $\mathrm{O}$ aparelho administrativo e os particulares luso-brasileiros reconheciam essa inevitabilidade e beneficiavam-se política e economicamente com isso: ao acolherem nos portos os navios de países aliados aos quais prestavam auxílio com produtos imprescindíveis à prossecução da viagem e com mão-de-obra ou, ainda, quando comerciavam e contrabandeavam mercadorias.

Parece claro que, para além do aspecto económico, o problema incida, de igual modo, na localização exacta das riquezas brasileiras e nos acessos a essas regiões centradas no interior do continente, a par do reconhecimento de uma debilidade militar, defensiva e demográfica óbvia que podia ser aproveitada pelas novas potências para invadir o território. Ora, esse medo/pânico relacionado com o temor de invasões e a preocupação com a segurança e defesa do território colonial estiveram presentes até finais do século XVIII e inícios do centénio seguinte entre os habitantes de todos os núcleos urbanos localizados desde o mar ao sertão, em todos os portos luso-brasileiros. ${ }^{20}$

Por outro lado, a ideia de uma invasão a território brasileiro não esteve de todo afastada do pensamento político e comercial de estrategas e mercadores de grosso trato das potências nascentes, com especial incidência entre franceses e ingleses que ponderavam os inúmeros benefícios advindos "do controle exclusivo do comércio e dos tesouros sul-americanos" e que se avaliavam mutuamente como concorrentes e opositores. Eles ignoravam ostensivamente a soberania portuguesa e os direitos coloniais adquiridos pela coroa portuguesa e reconhecidos à luz do direito e dos tratados internacionais. ${ }^{21}$ Esta afirmação clarifica-se quando se atende, por exemplo, na opinião de William Wyndham Grenville, secretário de estado dos Negócios Estrangeiros britânico entre 1791 e 1801, expressa do seguinte modo: "in the case of need, ceding to France two settlements which they /Portuguese/ say they have in the Philippine, instead of what France asks of them in Brazil. I conclude few things could be worse for us than letting France get any foot there". ${ }^{22}$ 
UM CONHECIMENTO RENOVADO: "INTELIGÊNCIA E LUZES”

DE HOMENS ESCLARECIDOS E IMPARCIAIS

Os diários e relatos de viagem escritos e divulgados ao longo do Setecentos, considerados nessa época como dos mais desejados e interessantes, transformaram gradualmente a navegação das águas do Atlântico Sul sendo tratada a princípio como algo confuso, inseguro e nublado para uma aventura que, embora de natureza singular e igualmente perigosa, se fazia de forma mais controlada e confiante. Passou-se a ser vista como segura e com maiores probabilidades de êxito, graças "à inteligência e luzes de geógrafos e mareantes esclarecidos e imparciais". ${ }^{23}$ Enquanto produto de um discurso científico, essa informação textual era avaliada pelos contemporâneos em uma dupla dimensão: como contributo válido à geografia e à ciência náutica do Setecentos e como registo histórico das viagens e derrotas dos navios.

Considerava-se que os autores de textos que congregassem uma habilidade especial no desenho e nos princípios gerais da observação eram os autores ideais que contribuíam, de forma mais válida que os outros, para uma "geography of the globe much corrected, the dangers of navigation considerably lessened; and the manners, arts and produce of foreign countries would have been much better known to us" (Chaplain, 1748, p.lxii). Assim, não deixa de ser interessante constatar que, no que respeita à colónia luso-brasileira, a maioria dos relatos e diários de navegação analisados estabelecem uma unidade intrínseca com as representações iconográficas e com a cartografia. Os textos descrevem, como acima se referiu, as viagens, as manobras náuticas, as instruções de navegação, os objectivos dos viajantes, as cidades, os habitantes, as maravilhas naturais e as potencialidades económicas. As imagens incidem sobre as entradas dos portos, as vistas das cidades e outros aspectos que permitissem o reconhecimento de um determinado local do mar (entrada da baía de Guanabara, ilha de Santa Catarina) ou que fossem particularmente impressionantes (Arco da Carioca). Ainda as representações cartográficas tomam a forma de cartas oceânicas ou litorâneas e de planos de barras. É Luciana de Lima Martins que associa, de forma pertinente, as cartas às práticas de navegação, isto é, à direcção de um navio por meio da astronomia, geometria e pela utilização de instrumentos de precisão, e articula os planos e vistas costeiras com a necessidade de os pilotos reconhecerem as barras de entrada de navios. ${ }^{24}$

Contudo, neste 'século das luzes', os textos, as imagens e os mapas permitem, acima de tudo, a materialização de experiências directas e pessoais, de 
observações feitas, vistas e comprovadas que assim se tornam transmissíveis. Consequentemente, os autores de relatos de viagem, observadores de fenómenos naturais e de sociedades humanas, dominam as técnicas básicas do desenho, adquirem experiência na forma como olham e registam o que vêem assim como dominam o manejo de instrumentos de precisão. Há, ao longo do século XVIII, uma preocupação constante de representar, de forma cada vez mais apurada, precisa e natural, a paisagem exótica e o mundo tropical. Essa representação é aperfeiçoada à medida que se sabe mais e se representa melhor, quando o olhar está mais habituado e os instrumentos ópticos permitem uma observação mais detalhada.

Textos e imagens são transmissores de um conhecimento não cristalizado, mas em permanente aperfeiçoamento e correcção que entrava em confronto quando as conclusões alcançadas eram divergentes. Na concretização desta afirmação, refira-se, a título de exemplo, que se Amadée François Frezier, graças à realização da viagem ao extremo setentrional da América do Sul entre 1712 e 1714 descrita na Relation du voyage de la Mer du Sud aux cotes $d u$ Chily et du Perou, fait les années 1712, 1713 et 1714, criticava a cartografia inglesa e francesa da costa brasileira produzida em período anterior. Esse mesmo autor seria corrigido, pouco tempo depois, pelo sr. De La Pallière Christy, no Journal du voyage de Joseph Royal a la Mer du Sud commencé l'année 1719 et fini l'année $1723 .^{25}$

$\mathrm{Na}$ construção desse discurso científico dialogam marinheiros, cartógrafos e desenhadores, académicos e cientistas, comerciantes e traficantes, piratas e corsários, holandeses, franceses, ingleses, portugueses, russos, suecos com as mais diversas motivações: políticas, científicas ou económicas. Confiavam em si e nas suas observações, nos métodos empíricos e nas luzes da razão. Um escrito, um desenho, um mapa era validados pelo seu autor "for they were not copied from the Works of others, or composed at home from imperfect accounts, given by incurious and unskillful observers" (Chaplain, 1748, p.lvi).

Nesse trabalho os viajantes socorriam-se igualmente das fontes que lhes estavam disponíveis, tendo embora uma atitude crítica diante da informação textual produzida por outros viajantes, de representações iconográficas e cartográficas, de produções naturais e etnológicas que recolhiam como garante do exótico dos mundos visitados e que enriqueciam as colecções de museus, de academias e de particulares por meio de testemunhos orais ouvidos de quem anteriormente tinha frequentado aquelas paragens. Ou, ainda, junto da população local, autóctone ou europeia, confrontando-se frequentemente tais informações, nesta circunstância, com as dificuldades causadas pelo "su- 
mo cuidado y particular silencio com que los naturales dificultam dar conocimiento de ellas, desfigurando la narracion o com excessivos hipérboles o com expressiones repugnantes a todo buen sentido". ${ }^{26}$

Essas representações tornavam-se em fonte de informação fiável com interesse prático para marinheiros, piratas, corsários, comerciantes em viagem, mas também tinham interesse intelectual junto da elite culta que permanecia nos salões e academias ou de estrategas e políticos que nunca deixavam os gabinetes. A informação veiculada tinha, portanto, interesse económico, estratégico, comercial e científico e pode-se inferir que tanto os velhos impérios como as novas potências dependiam das observações de viajantes inteligentes revertidas em benefício político, comercial e científico e em orgulho e glória do país afecto à viagem (Martins, 1998, p.145): "The 'search into knowledge' makes men 'serviceable to their country', since they teach kings and government, even as they open up channels for the transmission of both science and commodities back from the colonies to the metropolis". ${ }^{27}$

Esse discurso científico tinha, de igual modo, uma função didáctica e de entretenimento das massas. Consideravam que o esclarecimento dos compatriotas era uma obrigação de qualquer súbdito leal e valorizavam o conhecimento útil, muito particularmente quando clarificava aspectos até então desconhecidos. Se, como anteriormente afirmei, é verdade incontestável que os relatos dos viajantes incidiam sobre a linha de costa e em relação ao que era visto e directamente observado, não deixa de ser interessante reparar que, sempre que possível, dados sobre assuntos considerados interessantes, pela sua novidade e escassez de informação, que não tinham sido vistos nem observados, mas ouvidos de testemunhas fiáveis, eram incorporados nos textos impressos.

É o que se pode verificar, por exemplo, em $A$ voyage round the world in the years MDCCXL, I, II, III, IV onde o capelão Richard Walter relatou as aventuras de George Anson nos Mares do Sul. Aqui, maior informação sobre a história do continente sul-americano e, mais particularmente, sobre a colónia brasileira é incluída, juntamente com dados sobre a descoberta, localização, exploração, quantificação e rotas de contrabando de dois minerais de grande estima para os europeus, o ouro e o diamante. Sobre isso há o relato a seguir: "And as the Brazilian gold and diamonds are subject, about which, from their novelty, very few particulars have been hitherto published, I conceive this account I had collected of them would appear to the reader to be neither a tripling nor a useless digression". O principal responsável pela transmissão de uma informação que era tão ciosamente guardada pela coroa portuguesa, entidades 
administrativas e moradores da colónia teria sido uma visita habitual de Anson durante a sua permanência em Santa Catarina: o governador do Rio Grande (Chaplain, p.53, 47, 50).

Nesta análise não quero deixar de referir uma questão que, sendo pontual, é reveladora da natureza das "redes de informação e do conhecimento" que se constituíam na Europa, e mais precisamente na Inglaterra, sobre as questões ultramarinas. Afirma-se no relato da viagem de Anson que: "It was at last confirmed by skilful Jewellers in Europe, consulted on this occasion, that the stones thus found in Brazil were truly diamonds, many of which were not inferiour either in lustre, or in any other quality to those of the East-Indies" (Chaplain, 1748, p.48). Não deixa de ser interessante associar essa informação com uma carta publicada nas Philosophical Transactions, em 1745, por John Elliot, fellow da Royal Society, na qual se relatavam experiências feitas com diamantes do Brasil e das Índias Ocidentais com o objectivo de comprovar a qualidade das pedras, concluindo-se que não havia diferença significativa entre umas e outras. ${ }^{28}$ É relevante constatar que, três anos depois de ser publicada em uma revista científica direccionada para uma elite iniciada, essa informação era utilizada por Richard Walter, capelão do navio Centurion, num relato de viagem que pretendia ser também um livro de aventuras dirigido a uma audiência bastante mais vasta do que o público leitor das Philosophical Transactions.

Importa, de igual modo, considerar que os relatos descrevendo as viagens mirabolantes e aventurosas que implicavam a travessia do mar-oceano e o contacto com outra natureza e outra humanidade aumentaram gradualmente durante o período em análise. De igual modo, as descrições particulares, feitas à margem dos relatos oficiais e das exigências de disciplina naval a que as tripulações e capelães das frotas estavam sujeitas, proliferaram com cientistas, mercadores e outros membros da sociedade civil a bordo a tornarem-se autores credíveis e atractivos aos olhos de um público interessado, mas sem formação especializada nos domínios da náutica ou das ciências naturais. Face à crescente procura popular, os membros da tripulação e passageiros encontravam na edição dos relatos, escritos numa linguagem facilmente compreendida pelos seus compatriotas, uma fonte de rendimento não desprezível.

Muitos desses relatos foram publicados em livros de pequeno formato, sem estampas ou vinhetas e com um número reduzido de mapas, sendo, por isso, o seu preço accessível; outros foram publicados em fascículos em vários números de periódicos com grande tiragem; ou ainda em várias versões (abre- 
viadas, populares, para jovens), de forma a corresponder à curiosidade e a servir de entretenimento a um público cada vez mais interessado e atento (Chaplain, 1748, p.iv). O interesse e popularidade desse tipo de literatura fica claramente comprovado com, por exemplo, A voyage round the world in the years MDCCXL, I, II, III, IV by George Anson. O relato foi editado pela primeira vez em 1748 e conheceu quinze edições ilustradas com cartas e vistas até 1776.

Muitos desses relatos extrapolaram fronteiras graças às traduções, que muito contribuíram para reformular a imagem que a Europa letrada e iletrada tinha da colónia brasileira. Em francês, holandês, alemão e italiano, as viagens dos marinheiros ingleses eram divulgadas junto às camadas menos cultas que não dominavam as 'línguas da ciência' setecentista. ${ }^{29}$

Apesar dessa notória actividade editorial e como anteriormente mencionei, encontram-se ainda nos arquivos e bibliotecas da Europa muitas descrições de viagens inéditas. Há igualmente que ponderar que, mesmo quando impressos, alguns desses relatos não eram facilmente acessíveis e não podiam ser facilmente utilizados em viagens realizadas posteriormente. Tampouco eram suficientemente valorizados pela literatura de viagens da época porque se restringiam à costa e às cidades portuárias, além de apresentar pouquíssimas informações acerca do interior do território e não descrever seus habitantes primitivos (Payne, 1997, p.176). Os ameríndios são, de resto, 'os grandes ausentes' desses relatos, que fazem incidir as suas observações na população integrada nos núcleos urbanos e que referem, de forma vaga, o mosaico étnico e cultural que constituía cidades como o Rio de Janeiro ou a Bahia do século XVIII.

Apesar da vontade notória dos viajantes setecentistas ingleses em darem a reconhecer o Brasil através dos seus relatos de viagem, é inegável o desconhecimento que os europeus tinham sobre os domínios sul-americanos do Rei Fidelíssimo no inícios do centénio seguinte, conforme reconhece Thomas Lindley em 1808: "Notwithstanding the many voyages and travels that have lately been published and the addition science has received in geographical information, Brasil continues in a manner hidden, as to the world in general. All endeavours to gain information respecting it being industriously repressed by the Portuguese government, both in the colony itself and in Europe" (Lindley, cit., p.xi).

O ano de 1808 traria a inversão dessa situação com a abertura dos portos e com a autorização das viagens e permanência de súbditos britânicos em 
solo brasileiro. Instituições como a Royal Society, a Royal Geographical Society e os Kew Garden dariam corpo à curiosidade até aqui reprimida, organizando e patrocinando viagens de exploração. Por seu turno, as editoras de Paternoster Row e da Strand publicariam tanto narrativas de viagem recentemente escritas por viajantes naturalistas como colectâneas históricas de navegação e descoberta, de que A general collection of the best and most interesting voyages and travels in all parts of the world; many of which are now first translated into English digested on a new plan, de John Pikerton, é exemplo. ${ }^{30}$

Essa política científica e editorial não reflectia só o interesse da população, em geral, pela aventura, o exótico e o pitoresco, nem tampouco o das academias elitistas aristocráticas pelo conhecimento ligado à ciência, à navegação transatlântica e ao comércio internacional que via na comercialização e transformação das matérias-primas brasileiras uma fonte de lucro considerável em um país que iniciava a Revolução Industrial. A ciência, as viagens científicas e a divulgação dos seus resultados eram, para além do mais, um instrumento do Estado britânico para legitimar o poder territorial e soberano sobre os seus domínios coloniais ou o domínio comercial sobre as colónias de outros países e de outras zonas do universo da época. A competição política, estratégica, marítima, científica e económica era sobretudo com a França e o Império Francês e não diminuiu com o fim da guerra, depois de Napoleão ser aprisionado na ilha de Santa Helena.

Durante o século XVIII, a navegação, a ciência e a aventura desses homens, expressas sob a forma de relatos e diários de viagens, contribuíram significativamente para a glorificação das façanhas individuais de aventureiros e cientistas ingleses. Contudo, essas viagens aventurosas e o conhecimento científico associado contribuíam não apenas para a exaltação dos feitos individuais, mas, acima de tudo, glorificavam a nação a que esses heróis pertenciam - a Inglaterra. Propiciavam-lhe uma posição vantajosa no nível político, comercial e científico em escala mundial e contribuíam ainda para que, na construção de um saber supranacional/europeu acerca de lugares e populações dos domínios coloniais remotos, esse país ocupasse um lugar destacado.

\section{NOTAS}

${ }^{1}$ Luciana de Lima Martins. O Rio de Janeiro dos viajantes. O olhar britânico (18001850). Rio de Janeiro: Jorge Zahar, 2001, p.12; idem, “A naturalist's vision of the tropics: Charles Darwin and the Brazilian landscape", Singapure Journal of Tropical Geo- 
graphy, v.21, n.1, 2000, p.19-33; Jeanine Potelet. "Le Brésil vu par les voyageurs et les marins français, 1816-1840. Temoignages et images”. Paris: l'Harmattan, 1993.

${ }^{2}$ A esse respeito e para os fellows portugueses admitidos na Royal Society durante o século XVIII ver o artigo de Ângela Domingues, "Imprensa científica e imagem do Brasil colonial: a análise de dois casos" em $\mathrm{O}$ reino, o mar e as ilhas. Estudos em Homenagem a Artur Teodoro de Matos, coordenação de Avelino de Freitas de Meneses e João Paulo Oliveira e Costa. Lisboa e Ponta Delgada: Centro de História de AlémMar/FCSH/UNL e Universidade dos Açores. v.II, 2007, particularmente p.928 ss.

${ }^{3}$ Yasmine Marcil. "Le voyageur dans la presse périodique du XVIIIe siècle". Disponível em: revuefrancaise.free.fr/Marcil.htm.

${ }^{4}$ Ângela Domingues, 2007, p.905 ss; idem, "Viagens científicas e divulgação cartográfica”.em A Nova Lusitânia. Imagens cartográficas do Brasil nas colecções da Biblioteca Nacional (1700-1822). Lisboa: Comissão Nacional para as Comemorações dos Descobrimentos Portugueses, 2001. p.70.

${ }^{5}$ Para o conceito de ciência como actividade com repercussão social e filantrópica na passagem do século XVIII para o XIX ver Lorelai Kury. "Auguste de Saint-Hilaire, viajante exemplar". Disponível em: www.intellectus.uerj.br/Textos/Ano2n1/Texto\%20 de\%20\%20Lorelai\%20Kury.pdf.

${ }^{6}$ Chaplain Richard Walter. A voyage round the world in the years MDCCXL, I, II, III, IV by George Anson, esquire, commander in chief of the Squadron of His Majesty's ship's sent upon an expedition to the South Seas, compiled by Richard Walter, MA, chaplain of His Majesty's ship the Centurion, in that expedition. London: John \& Paul Knapton, 1748. p.lxii.

${ }^{7}$ Não obstante o que é afirmado, o incumprimento das leis relativas à proibição da fixação de estrangeiros é notório ao longo do período em análise, confirmando-se a presença significativa de franceses e ingleses no litoral brasileiro. Ver: Maria Fernanda Bicalho. A cidade e o Império. O Rio de Janeiro no século XVIII. Rio de Janeiro: Civilização Brasileira, 2003. p.37.

${ }^{8}$ Veja-se, por exemplo, a importância dos relatos de piratas e corsários no mapa de Nicolas de Fer, Le Brésil. Dont les Cotes sont divisées en Capitaineries, dresée sur les derniers Relations de Filibustiers et Fameux Voyageurs (Biblioteca Nacional, Cartografia, CC 1327; cf. Maria Fernanda Bicalho, 2003, p.106). Para o exemplo inglês cf. por exemplo "Relatório de Charles Solander a Earl de Morton, presidente da Royal Society, reparando no desconhecimento científico do vice-rei do Brasil e de outros notáveis, datado de 1 de Dezembro de 1768" (British Library, Miscellanious Papers, Add. 34 733, fl. 38). Outro exemplo é a forma como Banks se define perante a mesma personalidade: homem de honra, suficientemente rico para financiar uma expedição científica, desinteressado de aspectos militares ou proventos económicos. Sobre as noções de honra e desinteresse científico associadas à aristocracia científica britânica veja-se o 
artigo de Anne Secord, "Corresponding interests artisans and gentlemen in the nineteenth-century Natural History". British Journal for the History of Science, v.27, n.4, dez. 1994, p.384; veja-se ainda John Turnbull que considera que os portugueses se comportam de forma pouco civilizada em relação aos ingleses (Jean Marcel Carvalho França. "Um visitante inglês na Bahia de 1800". Revista de História, v.2, n.22, 2003, p.239).

${ }^{9}$ George Anson, Barão Anson of Sorbet, era membro da Royal Society, admitido a 5 dez. 1745 (Chaplain, 1748, p.42 ss).

${ }^{10} \mathrm{O}$ governador era também acusado de traficar com os espanhóis do Rio da Prata e de ter avisado as autoridades de Buenos Aires da chegada dos ingleses (Chaplain, 1748, p.45 ss).

${ }^{11}$ Resposta de Rolim de Moura a Joseph Banks, datada de 17 nov..1768 (British Library, Miscellaneous Papers, Add. 34 733, fl. 43v).

${ }^{12}$ Memória de Joseph Banks, esquire, ao conde Rolim de Moura, vice-rei e governador-geral do Brasil, de 17 nov. 1768 (British Library, Miscellaneous Papers, Add. 34 733, fl. 37 e Sterling Memorial Library, Sir Joseph Banks Papers, Manuscripts and Archives, Mss. 58).

${ }^{13}$ Patrick O'Brian, Joseph Banks. A life. London: The Harvill Press, 1987. p.77-78.

${ }^{14}$ Arthur Bowes Smith, diário da viagem do navio Lady Penrhyn da First Fleat, na sua viagem para as colónias australianas e Botany Bay, transportando mulheres degredadas (British Library, Journal of Arthur Bowes Smith, Add. 47 966, 1787, p.19v-24).

${ }^{15}$ Thomas Lindley, Authentic narrative of a voyage from the Cape of Good Hope to Brazil, a Portuguese settlement in South America in 1802, 1803; and terminating in the seizure of a British vessel; the imprisonment of the author, his wife, and ship's crew by the governor's orders with general sketches of the country, its natural productions, colonial inhabitants, etc, p.xxi; p.xxvii.

${ }^{16}$ Bill M. Donovan. "Rio de Janeiro and Portugal's trans-oceanic empire, 1700-1750". Proceedings of the International Colloquium on the Portuguese and the Pacific. Santa Barbara: University of California, Centre for Portuguese Studies, 1995. p.238-239.

${ }^{17}$ Thomas Lindley, cit., p.ix. Este é também um argumento utilizado pelas autoridades luso-brasileiras. Como exemplo, considere-se a seguinte resposta de D. António Rolim de Moura a Joseph Banks: a proibição de desembarque destina-se a evitar a introdução de mercadorias estrangeiras "than those brought from the ports of Portugal in Europe" que possam causar danos ao comércio colonial (British Library, Miscellanious Papers, Add. 34 733, fl. 43v, de 20 nov. 1768).

${ }^{18}$ Luciana Lima Martins. "Navigating in tropical waters: British maritime views of Rio de Janeiro”. Imago Mundi, v.50, 1998, p.145. 
${ }^{19}$ Maria Fernanda Bicalho. A cidade e o império: o Rio de Janeiro no século XVIII. Rio de Janeiro: Civilização Brasileira, 2003. p.109.

${ }^{20}$ British Library, Miscellaneous Papers, Add. 34 733, fl. 43v. Cf. Relato de John Turnbull e a descrição que faz da Baía de Todos os Santos e da reacção da população ao navio inglês em que viajava, cit. em França, 2003, p.232; Maria Fernanda Bicalho. "Cotidianos, medo, revolta e poder no Rio de Janeiro no século XVIII: um estudo sobre as invasões". Do Tratado de Tordesilhas (1494) ao Tratado de Madrid (1750), coord. de Maria Helena Carvalho dos Santos. Lisboa: Sociedade Portuguesa de Estudos do século XVIII, 1994. p.311-321.

${ }^{21}$ Carta de Lord Auckland a Lord Grenville de 14 nov. 1807 (British Library, Historical Manuscripts Commission, Reports on the manuscripts of JB Fortescue, esq., preserved at Dropmore, v.IX, London, printed for His Majesty's Stationery Office, 1915, p.143; John Turnbull cit. em França, 2003, p.238-239.

${ }^{22}$ Carta de Lord Grenville a Henry Dundas de 11 dez. 1798, British Library, Historical Manuscripts Commission, Reports on the manuscripts of JB Fortescue, esq., preserved at Dropmore, v.IV, London, printed for His Majesty's Stationery Office, 1905, p.410.

${ }^{23}$ Essa frase é elucidativa da forma como os homens ilustrados se pensavam e definiam (British Library, Manuscritos do Paraguay, Add. 13 979, fl. 347-348).

${ }^{24}$ Chaplain, 1748, p.40. Sabemos que o capitão Cook a bordo do Endeavour desenhou, em 1768, a cidade do Rio de Janeiro durante a sua permanência na Baía de Guanabara (Luciana de Lima Martins, 1998, p.145). Para a iconografia veja-se, também, John Borrow's travels in China and Conchin China, um álbum composto por desenhos de várias partes do mundo. Os do Brasil foram efectuados em 1792 por William Alexander, que constituía a missão de Lord Macartney à China (British Library, Original drawings by Alexander and Daniels, Add. 33931 [fls. 21, 22, 23, 24, 25, 26, 27, 28] e Add. 55300 [fls. 3, 4, 5, 6]). Cf. Luciana de Lima Martins, 1998, p.151.

${ }^{25}$ Ângela Domingues, 2001, p.69-70; Amadée François Frezier, na Relation du voyage de la Mer du Sud aux cotes du Chily et du Perou, fait les années 1712, 1713 et 1714, Paris, Chez Jean Geoffroy Nyon, Etienne Ganeau et Jacques Quillau, 1716; Journal du voyage de Joseph Royal a la Mer du Sud commencé l'anee 1719 et fini l'année 1723 par le Sr. De La Pallière Christy (British Library, Add. 52 420).

${ }^{26}$ British Library, Brasil. Tratados vários, Add. 17 619, fl. 34.

${ }^{27}$ Anna Neil. "Buccaneer ethnography: nature, culture and nation in the Journals of William Dampier”. Eighteenth-century Studies, v.33, n.2, 1999-2000, p.165-180.

28 "A letter from Mr. John Elliot FRS to the President, concerning the specific gravity of diamonds" (read 4 July 1745). Philosophical Transactions, v.43, 1744-1745, p.468472 .

${ }^{29}$ Anthony Payne. "The publication and readership of voyage journals in the Age of 
Vancouver, 1730-1830". Stephen Haycox, James Barnett \& Caedmon Liburd. Enlightenment and exploration in the North Pacific (1741-1805), Seattle \& Londres: Cook Inlet Historical Society, University of Washington Press, 1997, p.180; um exemplo elucidativo do que afirmamos pode ser consultado em Rosemary Erika Horch, "Notas bibliográficas sobre a obra do princípe Maximiliano de Wied Neuwied”. Oceanos, n.24, out.-dez. 1995, p.102-109.

${ }^{30}$ Ângela Domingues. "O Brasil de Maximiliano de Wied. Neuwied ou as aventuras de um príncipe alemão em viagem por terras brasileiras". Oceanos, n.24, out.-dez. 1995, p.40; John Pikerton, A general collection of the best and most interesting voyages and travels in all parts of the world; many of which are now first translated into English digested on a new plan, v.XIV, London, printed for Longman, Rees, Ormes and Brown, Paternester Row; and Cadell and Davies in the Strand, 1813.

Artigo recebido em janeiro de 2008. Aprovado em abril de 2008. 